\title{
Global Health Master's Students: Demographics and Career Goals
}

\author{
Ashti A. Doobay-Persaud ${ }^{1,2 *}$, Shannon R. Galvin ${ }^{1,3}$, Natalie E. Sheneman $^{1}$ and \\ Robert L. Murphy ${ }^{1,3}$
}

${ }^{1}$ Center for Global Health, Northwestern University Feinberg School of Medicine, Chicago, IL, United States, ${ }^{2}$ Division of Hospital Medicine, Center for Global Health, Northwestern University Feinberg School of Medicine, Chicago, IL, United States, ${ }^{3}$ Division of Infectious Disease, Center for Global Health, Northwestern University Feinberg School of Medicine, Chicago, IL, United States

\section{OPEN ACCESS}

Edited by:

John R. Finnegan,

University of Minnesota,

United States

Reviewed by:

Darcell P. Scharff,

Saint Louis University, United States

Todd F. Grant,

University of Minnesota,

United States

*Correspondence:

Ashti A. Doobay-Persaud a-doobay-persaud@northwestern.edu

Specialty section:

This article was submitted to Public Health Education and

Promotion, a section of the journal Frontiers in Education

Received: 27 February 2017

Accepted: 04 May 2017

Published: 23 May 2017

Citation:

Doobay-Persaud AA, Galvin SR Sheneman NE and Murphy RL (2017) Global Health Master's Students: Demographics and Career Goals.

Front. Educ. 2:23.

doi: 10.3389/feduc.2017.00023
The Master of Science in Global Health (MSGH) at Northwestern University (NU) is a new competency-based graduate degree program designed to prepare students to enter the global health workforce. The purpose of our research is to determine the market characteristics for this degree, provide student backgrounds that will guide curricular and programmatic improvements, and determine if these students intend to pursue careers in global health. This study examines survey responses from students admitted to the MSGH program between 2014 and 2015. Survey data were collected by the NU School of Professional Studies as a part of the online admissions application process. During the same period, all active students in the program were invited to complete a separate, online survey asking about their global health experience, skills, and career goals. Application responses were analyzed using descriptive statistics. Free-text responses from the survey were hand coded using 10 categorical variables developed through an inductive process. Fifty-four individuals were admitted to the MSGH program within 12 months of its inception. Of these, $78 \%$ were female, and the average age was 36 years. Of those who responded to questions about current employment, 57\% were working in a health science field, $11 \%$ in government or public administration, and less than $10 \%$ responded in all other categories. Responses from the online survey revealed that most students had some prior global health experiences primarily in the medicine and mission/ volunteer categories, 45 and 50\%, respectively. Responses regarding career aspirations were spread evenly across categories, and nearly all students intended to join the global health workforce. Medicine was identified most frequently as a desired field for future careers (30\%), followed by government and policy (25\%). The wide variety of disciplines represented in students' previous work histories underscores and supports the interprofessional nature of the field and the workforce. This diversity extends to both educational backgrounds and prior field experience and necessitates pedagogical techniques that can appeal to a wide array of students, particularly a majority female population. Findings regarding desired future employment suggest that career advising will need to adapt to market demands, prioritizing project and program management-related careers.

Keywords: curriculum, workforce, demographics, admissions, interprofessional, master's, global health 


\section{INTRODUCTION}

In this era of globalization, foreign policy and antipoverty development agendas are becoming more comprehensive and interdisciplinary; and health interventions are routinely a component of any effective program (World Health Organization, Organisation for Economic Co-operation and Development, World Bank, 2008; World Health Organization, 2016). In response, demand for professionals equipped with a global health skill set has grown (Eichbaum et al., 2015), and US universities have, in turn, developed master's level degree programs in global health to meet the needs of job seekers in this field. Between 2001 and 2011, it is estimated that the number of comprehensive global health programs offered in the US rose from 6 to 78 (Matheson et al., 2014; Merson, 2014). Today's global health professionals require skills that are not taught in traditional healthcare-focused degree programs, such as a $\mathrm{MD}, \mathrm{RN}$, or $\mathrm{MPH}$. These programs are time and resource intensive and tend to focus primarily on the clinical, research, and practice skills required in these roles. The specific skills of cultural humility, flexibility, diplomacy, collaboration, resilience, systems thinking, communication, critical thinking, and sociopolitical awareness should be accompanied by deep content and contextual knowledge of global health (Jogerst et al., 2015; Lucas, 2016; Rudy et al., 2016). Although there are occasionally global health certificates, concentrations, and field experiences offered within these programs, preparing graduates for careers in global health is not the intent of most health degrees. Given that $74 \%$ of the current job offerings in global health require a master's degree or higher, as noted in a recent survey (Eichbaum et al., 2015), the need for graduate education with global health-specific training is well established.

The Master of Science in Global Health (MSGH) at Northwestern University (NU) is a new degree program focusing on the interprofessional competencies required specifically for careers in global health. The degree is offered through NU's School of Professional Studies (SPS) and represents a collaboration between SPS and the Feinberg School of Medicine's Center for Global Health (CGH). The SPS provides financial and administrative support and CGH is responsible for providing core faculty and developing curricula and course material. The final curriculum is representative of the most current set of global health competencies covering the following domains: (1) global burden of disease; (2) globalization of health and health care; (3) determinants of health; (4) capacity strengthening; (5) collaboration, partnering, and communication; (6) ethics; (7) professional practice; (8) health equity and social justice; (9) program management; (10) sociocultural and political awareness; and (11) strategic analysis (Jogerst et al., 2015; Doobay-Persaud, 2016). These peer-reviewed interprofessional competency domains, developed by the Consortium of Universities for Global Health (CUGH) Competency Subcommittee, are rooted in the original Association of Schools \& Programs of Public Health competency framework (Ablah et al., 2014). The degree is offered in an online and asynchronous format designed to accommodate nontraditional students, such as working adults and international students. The MSGH program is designed for health, engineering, business, psychology, anthropology, government and policy, and other professionals to gain targeted skills and translate their existing degrees into a global health context. Additional information about program goals is available on the MSGH website. Given both the recent introduction and the paucity of similar programs, the general characteristics of students pursuing MSGH degrees are not clearly defined.

Now in its third year, MSGH is undergoing a curriculum assessment and review. The purpose of our current research is threefold: (1) describe the characteristics of students seeking a master's level degree in global health, and specifically through online programs; (2) provide student background data to inform continuous improvements to the MSGH coursework and program design; and (3) determine whether students pursuing these advanced degrees intend to enter the global health workforce.

\section{METHODS}

Survey data was collected during this period by SPS through questions included in the online MSGH application for admission (Supplementary Material). Questions regarding age, educational background, and current employer were required responses, while gender, race, and additional employment details were optional. For this study, SPS shared responses to the required questions and the optional question regarding industry of employment. Survey responses from students admitted to the MSGH program between 2014 and 2015 were analyzed. Chi-square and Fisher exact tests were performed to examine differences between student types, and descriptive statistics were generated to describe the cohort.

During this first year of the program, all students classified as "active" were also invited to complete a separate, online selfassessment with survey questions related specifically to their global health experience, skills, and career goals. The "active" cohort was defined as all those who were matriculated into the program, although not all of them had enrolled in classes when surveyed. The online survey was emailed to all active students by the faculty director of MSGH. The survey asked respondents to provide information about their previous global health-related experience and their future plans related to global health, as well as their skill level in 11 defined global health competency areas (Jogerst et al., 2015). This competency data collection is ongoing and will be used for further curriculum assessment and improvement.

From the online survey, free-text responses to the items "Please briefly describe your previous experience related to global health?" and "What are your future plans related to global health?" were extracted, deidentified, and analyzed for common themes. Two of the authors employed hand coding using categorical variables developed through an inductive process, as no validated instruments to code global health experience are currently available. Each response was coded for all of the categories represented in the text; therefore, the coding attributes were not mutually exclusive. Reviewers completed the coding separately, and results of coding and any discrepancies were discussed until final categorizations were determined. From the coding, percentages were calculated out of the total number of responses for each question. 


\section{RESULTS}

For the 2015 academic year, SPS admitted 54 students to the MSGH program. Of these 54 students, 49 matriculated during this same period, becoming classified as "active" by SPS. All active students received an email invitation to complete the online survey. In total, 20 students completed the additional survey during the first year, corresponding to $40 \%$ of the active student population.

Analysis of applicant data reveals that 54 individuals were admitted to the MSGH program within 12 months of its inception. Of these, $78 \%(42 / 54)$ were female. The average age was 36 (22-67 years), with $22 \%(12 / 54)$ being younger than 25 years and $26 \%(14 / 54)$ being older than 45 years. Of note, $22 \%(12 / 54)$ of students had a degree in health care (MD or RN) (Table 1). Forty-seven applicants responded to the employment details. Fifty-seven percent of these individuals (27/47) were working in health science, $11 \%(5 / 47)$ in government or public administration, and under $10 \%$ working in each of the areas of education, information technology marketing/sales, and hospitality/tourism (Table 2; Figure 1).

All 20 respondents to the online survey filled out free-text responses to the "Previous Experience" and "Future Plans" fields. Through an inductive process, 10 categories were identified from responses to each question, and these were formalized into a coding scheme (Table 3 ). This analysis also revealed which students had previous global health field experience versus those who had none. Distinct responses regarding previous experience and future plans were coded according to the devised scheme.

The students' previous global health experiences fell overwhelmingly in the "Medicine" and "Mission Trip/Volunteer" categories, 45\% (9/20) and 50\% (10/20), respectively, with smaller numbers of responses representing "Business/Industry," "Non-profit/Non-Governmental Organization (NGO)," "Epidemiology," and "Government/Policy." If the responses were unclear, they were categorized as "Unknown/Unable to Categorize" (Table 3; Figure 2). Three respondents fell into this last category. Coded responses about future careers were spread more evenly across the categories. All professional categories were represented in at least two individual text responses outside of "Mission Trip/Volunteer" with zero responses. "Medicine" had the highest response rate with $30 \%(6 / 20)$ of coded responses, followed by "Government/Policy" with 25\% (5/20). "Non-profit/ Non-Governmental Organization," "Project Management," "Undecided," and "Unknown/Unable to Categorize" all had low response rates of $10 \%(2 / 20)$ or less (Table 3; Figure 2).

\section{DISCUSSION}

This study provides some initial insight into the characteristics of students seeking master's level education in global health. These data can inform graduate schools as they consider the structure of their global health programs, design curricula to complement prior student knowledge, and target the novel skill set necessary for this discipline. For example, programs should be aware of the
TABLE 1 | Gender, age, and clinical degree, from Master of Science in Global Health application data.

\begin{tabular}{lcc}
\hline Characteristic & $\boldsymbol{n}$ or Mean & Percentage (total $\boldsymbol{N}=\mathbf{5 4})$ \\
\hline Female & 42 & 77.78 \\
Age Range (22-67 years) & 36 & \\
Under 25 years & 12 & 22.22 \\
Over 45 years & 14 & 25.93 \\
MD/RN & 12 & 22.22 \\
Non-MD/RN & 42 & 77.78 \\
\hline
\end{tabular}

TABLE 2 | Industry of employment, from Master of Science in Global Health application data.

\begin{tabular}{lrc}
\hline Industry & $\boldsymbol{n}$ & Percentage (total $\mathbf{N}=\mathbf{4 7}$ ) \\
\hline Business management and administration & 2 & 4.26 \\
Education and training & 2 & 4.26 \\
Government and public administration & 5 & 10.64 \\
Health science & 27 & 57.45 \\
Hospitality and tourism & 2 & 4.26 \\
Human services & 1 & 2.13 \\
Information technology & 1 & 2.13 \\
Law/public safety and security & 3 & 6.38 \\
Marketing/sales and service & 2 & 4.26 \\
Mathematics and science & 1 & 2.13 \\
Technology and engineering & 1 & 2.13
\end{tabular}

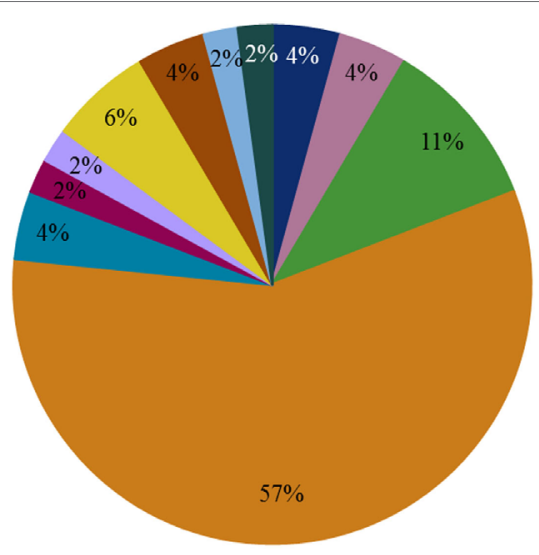

- Business Management and Administration Education and Training - Government and Public Administration

- Hospitality and Tourism Health Science Information Technology -Human Services Marketing/Sales and Service Law/Public Safety and Security Technology and Engineering

FIGURE 1 | Industry of employment, from Master of Science in Global Health (MSGH) application data.

overwhelmingly female interest in global health education and the implications for gender-based obstacles like health and safety issues and career longevity (Downs et al., 2014).

The wide variety of disciplines represented in students' previous work histories underscores and supports the interprofessional nature of the field and the workforce. This diversity is encouraging as we aim to educate the next generation of global 
TABLE 3 | Free-text survey responses from Master of Science in Global Health students, coding global health experience and future plans for industry.

n Percentage (total $N=20$ )

Please briefly describe your previous experience related to global health? ("Previous Experience")"

Medicine: doctor, clinical, nurse, RN, medical school, medicine, medical, physician, EMT, pharmacy

Epidemiology: surveillance, epidemiology, track [disease] Government/policy: policy, military, diplomacy, health system

Business/industry: industry, company, entrepreneur, venture Academic: research, academic, university, education Non-profit/non-governmental organization (NGO): 501(c) (3), non-profit, NGO (specific non-profit or NGO name)

Mission trip/volunteer: mission, volunteer

Program management: program manager, program

management, program

None (reference career change)

Unknown/unable to categorize

What are your future plans related to global health? ("Future Plans") a

Medicine: doctor, clinical, nurse, RN, medical school, medicine, medical, physician, EMT, pharmacy

Epidemiology: surveillance, epidemiology, track [disease]

Government/policy: policy, military, diplomacy, health

system

Business/industry: industry, company, entrepreneur, venture Academic: research, academic, university, education Non-profit/non-governmental organization: 501(c)(3), non-profit, NGO (specific non-profit or NGO name)

Mission trip/volunteer: mission, volunteer

Program management: program manager, program

management, program

Undecided

Unknown/unable to categorize

$9 \quad 45$

1

${ }^{a}$ Categories are not mutually exclusive.

health practitioners and necessitates pedagogical techniques that can appeal to a wide array of students. Indeed, a 2016 report by the UN High-Level Commission on Health Employment and Economic Growth included promoting "intersectoral collaboration" as a key recommendation for meeting growing global healthcare needs (UN High-Level Commission on Health Employment and Economic Growth, 2016). The majority of students had previous global health experience as well as selfidentification in the health science field. These are features that may represent both desired admission criteria and applicant characteristics. We expected a high proportion of students with a health science background, specifically medical health professionals; therefore, the lower proportion of MDs and RNs in the student cohort was a surprising finding. In addition, the large number of students with experience on medical missions offers programs and educators an opportunity for dialog around this aspect of global health. This information can be used in curriculum design, particularly around the field experience, a common component in global health education. Finally, as global health educational programs grow, so do needs for measurement and programmatic improvement. To that end, our categorization scheme for global health field experiences and careers proposes

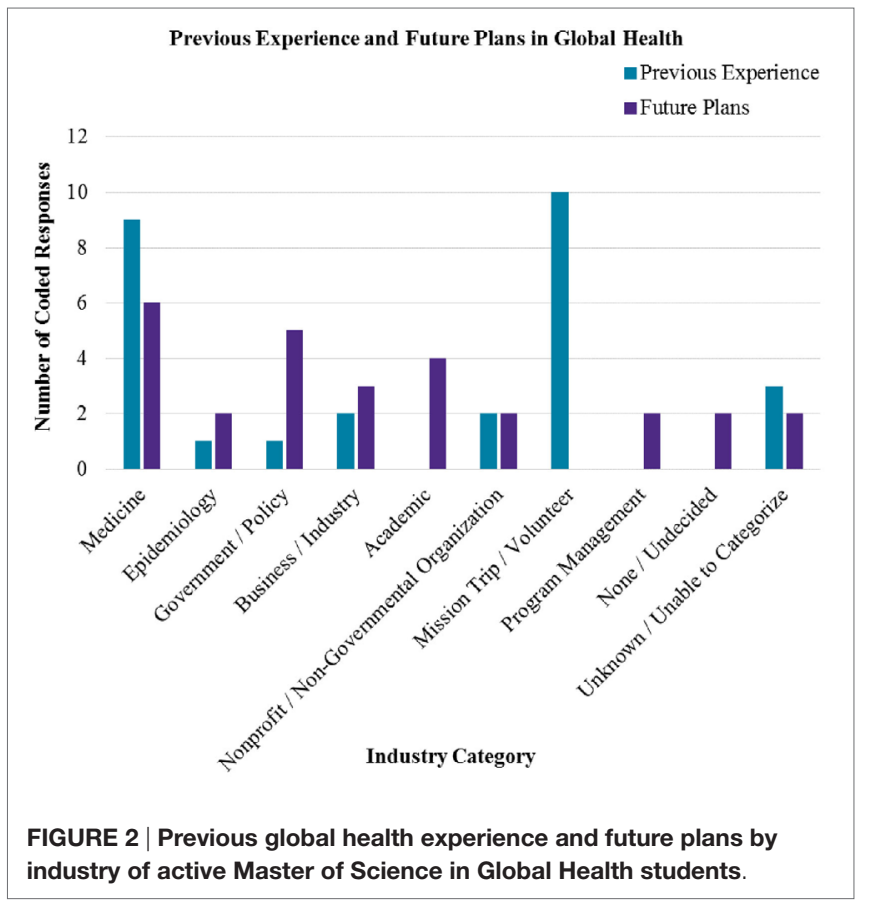

a standardized tool, which future educators can validate, expand, and improve.

Recent studies regarding employment in global health have revealed that most jobs are actually within the NGO and multinational organization sectors, with $84 \%$ of positions being related to program management (Eichbaum et al., 2015). This is in stark contrast to the low number of students who, upon entering the MSGH program, indicated seeking careers in this field of global health work. Based on this information, career advising by both faculty and staff will need to adapt to market realities. Instead, many of the students pursuing these degrees are hoping to go on to careers in medicine. The discrepancy between previous experiences in volunteer or medical mission work compared with future aspirations was significant. This could be due to the temporary nature of these missions, which typically lack a career trajectory and are frequently the entryway for students into the world of global health. This finding, however, may also reflect the changing language and principles around the model of medical service abroad (Loh et al., 2015).

\section{LIMITATIONS}

Limitations of our study include a small sample size, since the program is in its infancy, and a short period of time to collect application data and survey responses. The study did not attempt an in-depth analysis of students' prior global health experiences or future career aspirations. Follow-up through deeper qualitative research methods including focus groups, key informant, or semi-structured interviews could yield a richer picture of these particular global health students and potentially contribute more to a comprehensive overview of students seeking to graduate with degrees in global health. 


\section{CONCLUSION}

Nearly all of the MSGH students included in this study plan on incorporating global health into their future career plans, supporting our initial hypothesis that students applying to these programs represent the future global health workforce. Our study revealed pedagogically relevant learner demographics such as age and gender, significant prior experience in global health, and a diverse set of employment backgrounds. This information can serve as a learner needs assessment to align and improve the curriculum, enable faculty to leverage peerlearning opportunities, and target course material for diverse students.

In addition, while the CUGH competencies were developed for the global health learner, these competencies need validation and refinement for professionals who are not only preparing for long-term careers in the field, but are seeking expertise on a graduate degree level. Further exploration of career trajectories and skills desired by potential employers will inform MSGH curriculum design and program competencies. For instance, emerging research from employers cites both the importance and the absence of business effectiveness and interpersonal skills in the global health workforce (Rudy et al., 2016). Since many MSGH programs are nascent, efforts should be made to communicate the value of these degrees to global health employers and to align curricula with employer needs. Additional data from other programs will be necessary to truly assess student needs, target the most valuable skills, and effectively shape global health graduate education.

\section{REFERENCES}

Ablah, E., Biberman, D. A., Weist, E. M., Buekens, P., Bentley, M. E., Burke, D., et al. (2014). Improving global health education: development of a global health competency model. Am. J. Trop. Med. Hyg. 90, 560-565. doi:10.4269/ajtmh.130537

Doobay-Persaud, A. (2016). Educating an interprofessional workforce: evaluation of a competency-based MS in global health. Ann. Global Health 82, 350-351. doi:10.1016/j.aogh.2016.04.057

Downs, J. A., Reif, L. K., Hokororo, A., and Fitzgerald, D. W. (2014). Increasing women in leadership in global health. Acad. Med. 89, 1103-1107. doi:10.1097/ ACM.0000000000000369

Eichbaum, Q., Hoverman, A., Cherniak, W., Evert, J., Nezami, E., and Hall, T. (2015). Career opportunities in global health: a snapshot of the current employment landscape. J. Glob. Health 5, 010302. doi:10.7189/jogh.05. 010302

Jogerst, K., Callender, B., Adams, V., Evert, J., Fields, E., Hall, T., et al. (2015). Identifying interprofessional global health competencies for 21st-century health professionals. Ann. Glob. Health 81, 239-247. doi:10.1016/j.aogh. 2015.03.006

Loh, L. C., Cherniak, W., Dreifuss, B. A., Dacso, M. M., Lin, H. C., and Evert, J. (2015). Short term global health experiences and local partnership models: a framework. Global Health 11, 50. doi:10.1186/s12992-015-0135-7

Lucas, B. (2016). Getting the improvement habit. BMJ Qual. Samp. 25, 400-403. doi:10.1136/bmjqs-2015-005086

Matheson, A. I., Pfeiffer, J., Walson, J. L., and Holmes, K. (2014). Sustainability and Growth of University Global Health Programs: A Report of the CSIS Global Health Policy. Washington, DC: CSIS Global Health Policy Center.

Merson, M. H. (2014). University engagement in global health. N. Engl. J. Med. 370, 1676-1678. doi:10.1056/NEJMp1401124

\section{ETHICS STATEMENT}

The Northwestern University Institutional Review Board Office reviewed the protocol for this work and determined that it is exempt from the guidelines for research involving human subjects.

\section{AUTHOR CONTRIBUTIONS}

AD-P, SG, and NS made substantial contributions to the design of the study and the collection and interpretation of student survey data. AD-P, SG, NS, and RM participated in drafting the work and revising it critically for intellectual content relevant to global health education; gave final approval of the version to be published; and agreed to be accountable for all aspects of the work in ensuring that questions related to the accuracy or integrity of any part of the work are appropriately investigated and resolved.

\section{ACKNOWLEDGMENTS}

The authors would like to acknowledge Mary Brennan, Mary Cohen, Chris Peterson, and Therese Grohman of the School of Professional Studies for their support in completing this research.

\section{SUPPLEMENTARY MATERIAL}

The Supplementary Material for this article can be found online at http://journal.frontiersin.org/article/10.3389/feduc.2017.00023/ full\#supplementary-material.

Rudy, S., Wanchek, N., Godsted, D., Blackburn, M., and Mann, E. (2016). The PHI/ GHFP-II Employers' Study: the hidden barriers between domestic and global health careers and crucial competencies for success. Ann. Glob. Health 82, 1001-1009. doi:10.1016/j.aogh.2016.10.012

UN High-Level Commission on Health Employment and Economic Growth. (2016). Working for Health and Growth: Investing in the Health Workforce. Geneva: WHO

World Health Organization. (2016). World Health Statistics 2016: Monitoring Health for the SDGs. Geneva, Switzerland: World Health Organization.

World Health Organization, Organisation for Economic Co-operation and Development, World Bank. (2008). Effective Aid, Better Health: Report Prepared for the Accra High Level Forum on Aid Effectiveness. Switzerland: World Health Organization, Organisation for Economic Co-operation and Development, World Bank.

Conflict of Interest Statement: AD-P has nothing to disclose. SG reports research grants from Gilead Sciences, outside the submitted work. NS has nothing to disclose. $\mathrm{RM}$ is a member of the Independent Data Monitoring Committee for Gilead Sciences.

The reviewer, TG, and handling editor declared their shared affiliation, and the handling editor states that the process nevertheless met the standards of a fair and objective review.

Copyright (c) 2017 Doobay-Persaud, Galvin, Sheneman and Murphy. This is an open-access article distributed under the terms of the Creative Commons Attribution License (CC BY). The use, distribution or reproduction in other forums is permitted, provided the original author(s) or licensor are credited and that the original publication in this journal is cited, in accordance with accepted academic practice. No use, distribution or reproduction is permitted which does not comply with these terms. 